\title{
Cathodoluminescence and REBIC Study of Defects in Tin Oxide
}

\author{
D.Maestre, A.Cremades and J.Piqueras
}

\begin{abstract}
Cathodoluminescence (CL) and remote electron beam induced current (REBIC) in the scanning electron microscope (SEM) has been used to investigate the electron recombination mechanisms in tin oxide. Sintered material prepared from high purity powder has been found to show a strong dependence of the CL emission on the thermal treatments applied during sample preparation. SEM images show the presence of nane and microcrystalline grains. The correlation of the grain size and morphology with the optical emission is analysed by CL microscopy and spectroscopy. The evolution of the luminescence bands with mechanical milling shows a complex evolution of the $1.94 \mathrm{eV}$ and $2.58 \mathrm{eV}$ emissions which is explained by formation and recovery of defects during milling. REBIC measurements and imaging are used to characterize the formation of a potential barrier at the grain boundaries.
\end{abstract}

\section{I NTRODUCTION}

One of the reasons of the increasing interest on semiconducting oxides like $\mathrm{SnO}_{2}, \mathrm{TiO}_{2}, \mathrm{La} \mathrm{FeO}_{3}, \mathrm{SmFeO}_{3}$ and $\mathrm{In}_{2} \mathrm{O}_{3}$ is the application of nanocrystalline powders for gas sensing and gas monitoring devices [1]. According to accepted sensing mechanisms [2] grain-size reduction increases the sensitivity of the semiconducting oxides to the detection of gases. $\mathrm{SnO}_{2}$ has, in addition, other applications, as for instance in transparent electrodes and optoelectronic devices. The preparation of thick films, or sintered materials, from powders, often involves annealing in different atmospheres which results in materials with different optical and/or structural properties. The knowledge and understanding of the processing induced changes at a local scale would enable to improve the material properties related to the mentioned applications. In particular, grain boundaries in n-type $\mathrm{SnO}_{2}$ ceramics can trap electrons and form back to back Schottky barriers determining the transport properties of the free carriers in the sample. The recombination activity of extended defects such as dislocations and grain boundaries attracts much attention because of its technological importance since these defects control the electrical properties of the material. In this work $\mathrm{SnO}_{2}$ sintered ceramic samples were prepared from commercial powders and the influence of the sintering parameters, as annealing temperature, atmosphere and annealing time on the microstructure, defect distribution, local electrical activity and

D. Maestre, A. Cremades and J. Piqueras are with the Departmento de Física de Materiales, Facultad de Ciencias Físicas, Universidad Complutense de Madrid, 28040-Madrid, Spain,

E-mail: piqueras@fis.ucm.es luminescence of the samples has been investigated. Characterization with spatial resolution has been performed by means of the secondary electron, cathodoluminescence (CL) and remote electron beam induced current (REBIC) modes in the scanning electron microscope (SEM).

\section{EXPERIMENTAL}

The starting material used was commercial $\mathrm{SnO}_{2}$ powder formed by particles and aggregates of rounded particles with sizes of about $200 \mathrm{~nm}$. In order to reduce and obtain a more homogeneous particle size the powder was milled in a centrifugal ball mill for times of 30,60 and 100 hours respectively. The untreated and the milled powders were compacted to form disc shaped samples of about 7 $\mathrm{mm}$ diameter and $2 \mathrm{~mm}$ thickness. Some of the samples were then sintered in air at temperatures between $1000^{\circ} \mathrm{C}$ and $1500{ }^{\circ} \mathrm{C}$. Some of the air sintered samples were subsequently annealed in oxygen at $600^{\circ} \mathrm{C}$ and $900^{\circ} \mathrm{C}$.

The samples were observed in the secondary electron (SE) and CL and REBIC modes in a Hitachi S-2500 or a Leica 440 SEM at accelerating voltages ranging from 10 to $30 \mathrm{kV}$, at temperatures between $80 \mathrm{~K}$ and $300 \mathrm{~K}$.

\section{RESULTS AND DISCUSSION}

To study the effect of annealing temperature a set of samples was sintered in air from the starting powder without mechanical treatment at temperatures between $1000^{\circ} \mathrm{C}$ and $1500^{\circ} \mathrm{C}$ for 10 hours. The final crystal size ranges from about $200 \mathrm{~nm}$ after the $1000^{\circ} \mathrm{C}$ treatment to about $100 \mu \mathrm{m}$, in samples treated at $1500^{\circ} \mathrm{C}$. In the crystals of the samples treated at $1500^{\circ} \mathrm{C}$, charge effects appear during observations in the SEM revealing a reduced electrical conductivity. The total $\mathrm{CL}$ intensity of the samples depends on the annealing temperature. After the $1200^{\circ} \mathrm{C}$ treatment an intensity increase is observed while the $1500^{\circ} \mathrm{C}$ annealing causes an intensity reduction. Figure I shows representative CL spectra of the series of samples sintered in air as compared with the spectrum of the starting powder. Gaussian deconvolution of the spectra shows the presence in the different spectra of bands centered at about $1.94 \mathrm{eV}, 2.25 \mathrm{eV}$ and $2.58 \mathrm{eV}$. The large grain size and the well defined crystallographic faces in the samples sintered at $1500^{\circ} \mathrm{C}$ enabled to record $\mathrm{CL}$ images in which an enhanced luminescence at the grain boundaries is revealed (Figure2). 


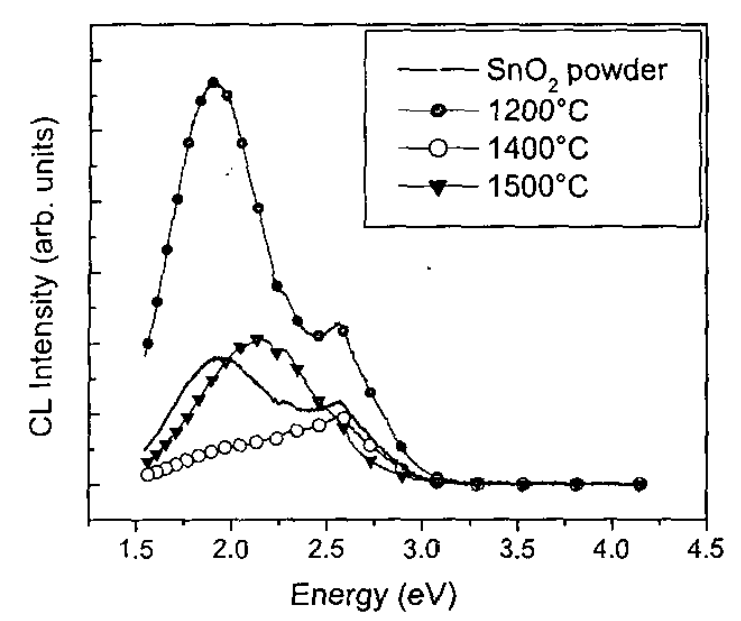

Fig. 1. CL spectra of initial powder and samples sintered at different temperatures.
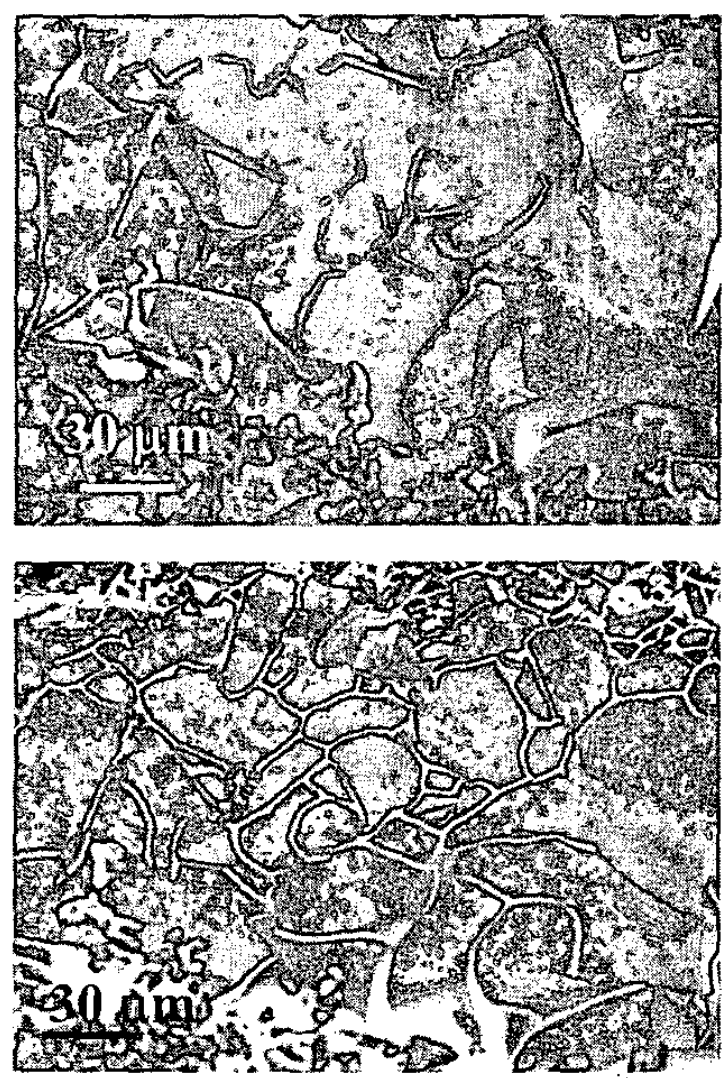

Fig. 2. a) $\mathrm{SE}$ and b) $\mathrm{CL}$ images of the same region of a sample sintered at $1500^{\circ} \mathrm{C}$. Bright grain boundaries are observed in the CL image.
The samples sintered in air were further annealed in oxygen for two hours at $600^{\circ} \mathrm{C}$ and $900^{\circ} \mathrm{C}$ respectively. These treatments produced either relative increase or decrease of the $1.94 \mathrm{eV}$ band depending on the sintering temperature of the sample, but no charge effects, related to a reduced conductivity, were observed in the SEM.

The effect of the previous milling time of the powders on the luminescence of the sintered samples is shown in Figure 3. It is observed that the shorter milling time of 30 hours causes the relative increase of the $2.58 \mathrm{eV}$ emission which decreases again by increasing milling time. The recovery effect observed for long milling times, which has been previously found in luminescence studies of milled $\mathrm{ZnO}$ [3], would be a consequence of the competition between defect creation and recovery which takes place during milling [4].

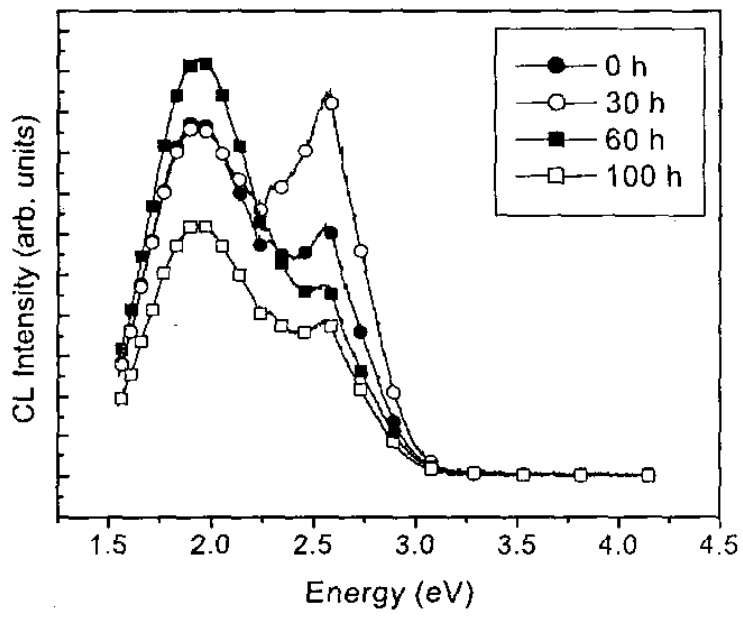

Fig. 3. CL spectra of samples with different milling times.

SE and REBIC images of samples with grain size of about $250 \mathrm{~nm}$ (sintering at $1200^{\circ} \mathrm{C}$ ) are shown in Figures $4 \mathrm{a}$ and $4 \mathrm{~b}$. The REBIC signal is associated to the grains whereas intergranular regions appear dark. When these samples are treated in oxygen at $600^{\circ} \mathrm{C}$ and $900^{\circ} \mathrm{C}$ for 2 hours the REBIC contrast decreases significantly as observed in Fig $4 \mathrm{c}$. CL images recorded for comparison show that for untreated samples the luminescence emission comes out homogeneously from the grain volume (not shown here) while for oxygen treated samples the luminescence centers are attracted to the grain boundaries (Figure 4d). 

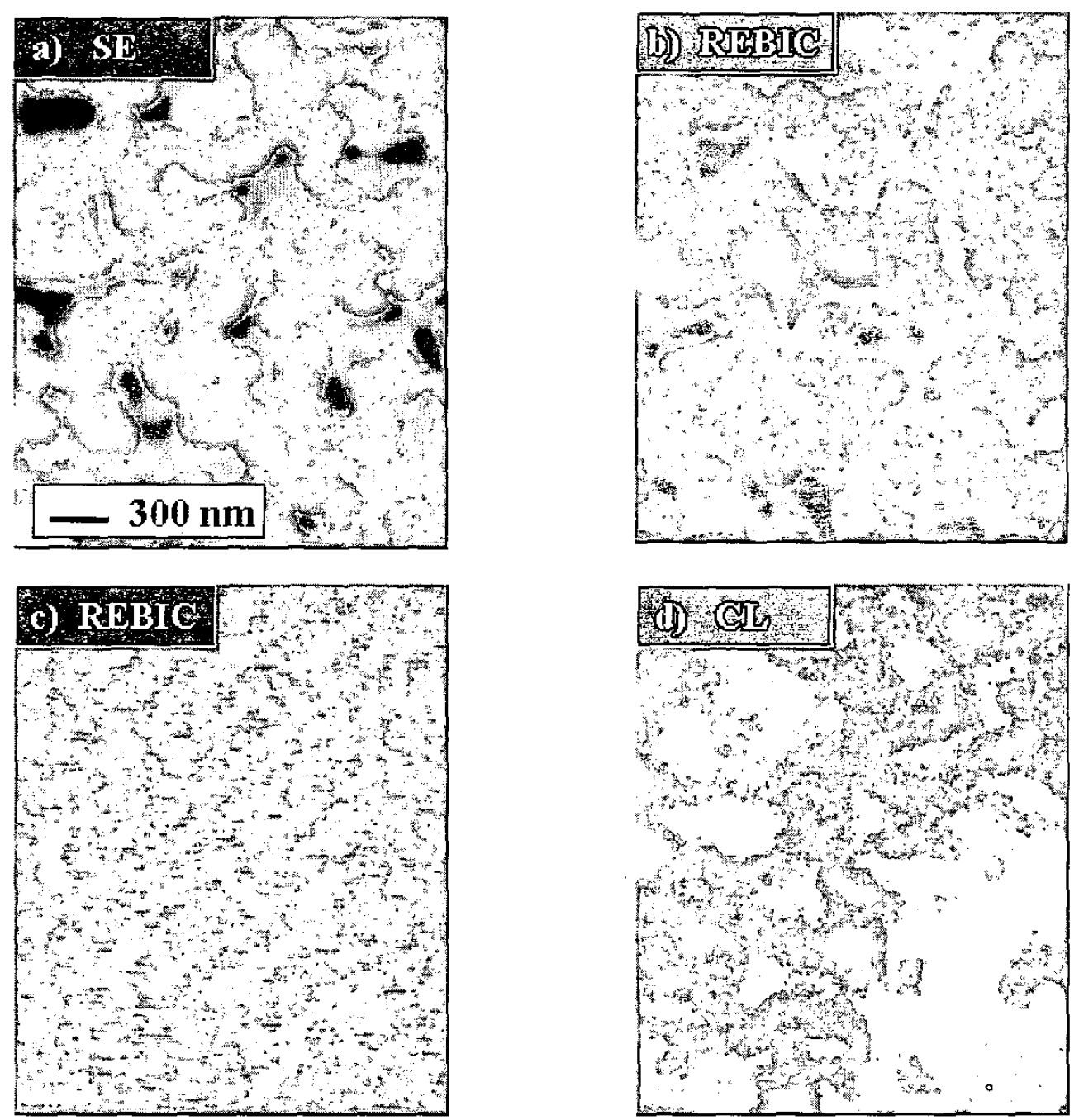

Fig. 4. a) SE and b) REBIC images of untreated samples sintered at $1200^{\circ} \mathrm{C}$. c) REBIC and d) $\mathrm{CL}$ images of a $\mathrm{O}_{2}$ treated sample for $2 \mathrm{~h}$ at $600^{\circ} \mathrm{C}$.

A characteristic REBIC contrast of charged defects [5]-[6] known as black-white contrast or peak and trough (PAT), appears at grain boundaries of samples sintered at $1500{ }^{\circ} \mathrm{C}$ and treated in oxygen for 2 hours at $600{ }^{\circ} \mathrm{C}$ (see Figure 5). This PAT contrast appears when the local electric field has opposite directions at each side of the barrier and can be modeled by two Schottky barriers back to back [7]. This shows the existence of a potential barrier at the boundary due to the presence of oxygen related defects.

The orange band, peaked in our case at $1.94 \mathrm{eV}$, has a complex behaviour during treatments in air and oxygen which would be related to changes in stoichiometry and defect structure. The band was found to increase during sintering in air at temperatures up to about $1200{ }^{\circ} \mathrm{C}$. The samples subsequently treated in oxygen did not show noticeable resistivity increase, as observed by the absence of charge effects in the SEM, which suggests that not significant reduction in oxygen vacancy concentration takes place during the treatments, although strong intensity changes of the $1.94 \mathrm{eV}$ band are observed. Since oxygen vacancies act as shallow donors in $\mathrm{SnO}_{2}$ with an energy of about $30 \mathrm{meV}$ below the conduction band [8]-[9], a reduction in oxygen vacancy concentration would cause a resistivity increase. On the other hand, the fact that sintering in air at $1500{ }^{\circ} \mathrm{C}$ causes the quenching of the 


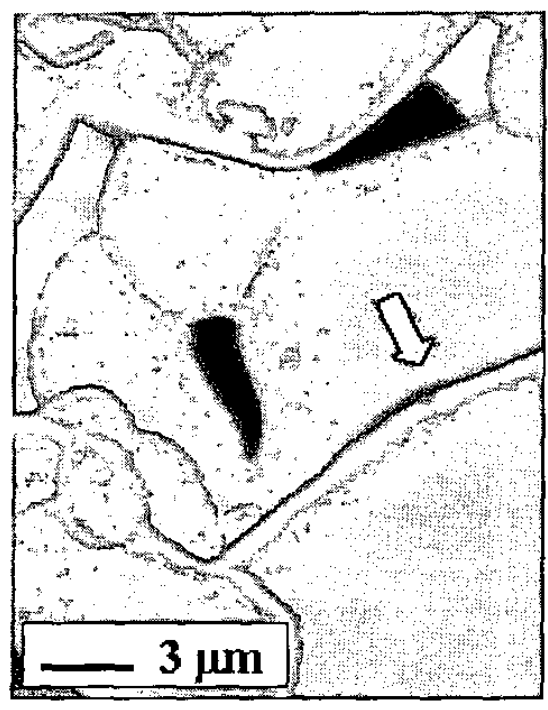

Fig. 5. REBIC image of samples sintered at $1500^{\circ} \mathrm{C}$ and treated in oxygen for 2 hours at $600^{\circ} \mathrm{C}$. A grain boundary showing the characteristic PAT contrast is marked by an arrow.

orange band and an associated resistivity increase, indicates that a component of the orange band is related to the presence of oxygen vacancies. Treatments causing the quenching of the orange band lead to a dominant green emission in the spectra, which indicates a different origin for the green $(2.25 \mathrm{eV})$ and orange $(1.94 \mathrm{eV})$ emissions observed. In addition to the green and orange bands, the CL spectra show a band peaked at about $2.58 \mathrm{eV}$ which has been observed to increase or even to become dominant after some of the sintering treatments in air or during ball milling for 30 hours. This emission was observed to be associated to certain crystal faces.

\section{CONCLUSION}

$\mathrm{CL}$ of sintered $\mathrm{SnO}_{2}$ shows the presence of bands at $2.58 \mathrm{eV}, 2.25 \mathrm{eV}$ and $1.94 \mathrm{eV}$ whose relative intensities depend on the sintering treatment. $\mathrm{CL}$ images reveal that the green $(2.25 \mathrm{eV})$ band is mainly associated to grain boundaries. The results indicate that the orange $(1.94 \mathrm{eV})$ band, which has a different origin than the green band, is complex and one of its components appears to be related to oxygen vacancies. Mechanical milling induces strong changes in the intensity of the $\mathrm{CL}$ bands at $1.94 \mathrm{eV}$ and $2.58 \mathrm{eV}$. The evolution of these bands with milling time shows the existence of formation and recovery of defects during milling. REBIC images show the presence of a potential barrier at grain boundaries due to an enhanced concentration of oxygen related defects in these regions.

\section{ACKNOWLEDGEMENT}

This work was supported by MCYT (Project MAT 2003-455).

\section{REFERENCES}

[1] G. Martinelli, M. C. Carotta, E. Traversa and G. Ghiotti, "Thick-Film Gas Sensors based on nano-sized semiconducting oxide powders", Materials Research Society Bulletin, 1999, vol. 24, pp. 30-36.

[2] C. Xu, J. Tamaki, N. Miura and N. Yamazoe, "Grain size effects on gas sensitivity of porous $\mathrm{SnO}_{2}$-based elements", Sensors and. Actuators B, 1991, vol. 3, pp. 147-155.

[3] R. Radoi, P. Fernández, J. Piqueras, M. Wiggins and J. Solis, "Luminescence properties of mechanically milled and laser irradiated ZnO", Nanotechnology, 2003, vol 14 (7), pp. 794-798.

[4] C. C. Koch, "The synthesis and structure of nanocrystalline materials produced by mechanical attrition: a review", 1993. Nanostructured Materials, vol 2 (2), pp. 109-129.

[5] G. Panin and E. Yakimov, "REBIC-SEM characterization of compound semiconductors", Semicond. Sci. Technol, 1992 Vol. 7 (1A), pp. A150-A153.

[6] D. B. Holt, B. Raza, and A. Wojcik, "EBIC studies of grain boundaries" Mater. Sci. Eng. B, 1996, vol. 42, pp. 14-23.

[7] E. Ziegler, W. Siegel, H. Blumtritt, and O. Breitenstein, "Electrical and EBIC investigations of $\mathrm{GaP}$ grain boundaries" Phys. Status Solidi A , 1982, vol.72, pp. 593-605.

[8] E. De Frésart, J. Darville and J.M.Gilles, "Surface properties of Tin Dioxide single crystals", Surf. Sci., 1983, vol. 126, pp. 518-522.

[9] D.F.Cox, T.B. Fryberger and S. Semancik, "Oxygen vacancies and defect electronic states on the $\mathrm{SnO}_{2}(110)-1 \times 1$ surface", 1988. Phys. Rev. B, 1998, vol. 38, pp. 2072-2083. 